\title{
A Study on Ecological Interface Design for Navy Ship's Radar Display
}

\author{
Young Hwan Park, Rohae Myung \\ School of Industrial Management Engineering, Korea University, Seoul, 136-713
}

\begin{abstract}
Objective: The aim of this study is developing the navigation radar display of navy ship with ecological interface design (EID) framework. Background: Navy ship radar operator must perform navigation support tasks by monitoring the complex and diverse information presented on the radar display. Current radar display is limited in effective navigation aid and response to an unusual state immediately. It is necessary to develop an effective radar display. Method: Ten navy radar operators performed a series of trials in a low-fidelity radar simulation in which they attempted to solve the problems of current navigation situation. Results: The result demonstrated that the ecological interface's performance was better than the existing radar display on performance time and subjective mental workload. Conclusion: This study expand EID study field to navy ship radar display and confirm ecological display is better than existing radar display in performance time, subjective mental work load. Application: The result of this study may help to improve navy ship navigation radar display currently in use.
\end{abstract}

Keywords: Ecological Interface Design(EID), Work Domain Analysis(WDA), Abstraction Hierarchy(AH)

\section{Introduction}

복잡하고 많은 양의 정보를 처리해야 하는 상황에서 작 업자들의 신속한 문제해결 및 의사결정을 위해서는 효과적 인 디스플레이를 설계하는 것은 중요하다. 해군 함정 레이 더 디스플레이 작업자들은 각종 상황에 따라 정확하고 신속 한 상황을 판단하고 결정할 수 있도록 지속적인 교육훈련을 받는다. 하지만, 함정에서 일어나는 모든 상황이 레이더 작 업자들의 교육훈련 내용과 일치하지는 않는다. 따라서, 해 군 함정의 레이더 디스플레이는 일반적인 상황은 물론 작 업자들이 일반적이지 않은 상황에 직면했을 때 무엇을 수 행해야 하는 지를 결정하고 대처하는데 도움이 될 수 있도 록 설계되어야 한다(Burns et al., 2005). 이러한 디스플레 이 설계를 위해 일반적인 상황뿐만 아니라, 일반적이지 않 은 상황에서도 효과적인 의사결정을 할 수 있도록 도와주
는 인터페이스 설계 방법론이 생태학적 인터페이스 디자인 (Ecological Interface Design, EID) 프레임웍이다(Vicente and Rasmussen, 1992). 지금까지 EID는 효과적인 문제 해결을 위해 Process Control이나 Aviation, Software Engineering, Command and Information Retrieval, 자동 차 계기판 그리고 도시철도 역사 내 안전 감시 시스템과 같 은 산업 분야(Burns and Hajdukiewicz, 2004; Burns, et al., 2008a; Nam et al., 2007; Lee et al., 2010)는 물론 Sonobuoy system(Chen et al., 2007), 항공기 관제 디스 플레이 (Ko and Myung, 2006) 와 같은 군사 분야에서도 사 용되어 왔으며, 현재에도 새로운 분야에 적용하기 위한 연구 가 지속되고 있다.

함정 레이더 인터페이스 분야는 지금까지 연구되고 적용 된 $\mathrm{EID}$ 작업영역의 특성과 많은 유사성을 가지고 있다. 우 선, 함정 레이더 인터페이스는 시스템의 목적이 명확하고, 레이더 운용 중 행해지는 많은 의사결정들은 함정 자체의 안

Corresponding Author: Rohae Myung. School of Industrial Management Engineering, Korea University, Seoul, 136-713.

Mobile: 010-8915-3392, E-mail: rmyung@korea.ac.kr

Copyright@2012 by Ergonomics Society of Korea(pISSN:1229-1684 eISSN:2093-8462). All right reserved.

(c) This is an open-access article distributed under the terms of the Creative Commons Attribution Non-Commercial License(http://creativecommons.org/licenses/by-nc/3.0/), which permits unrestricted non-commercial use, distribution, and reproduction in any medium, provided the original work is properly cited. 
전에 큰 영향을 미친다. 또한, 평상시 시스템의 통제는 정해 진 절차에 의해서 이루어 지고 있으나 일반적이지 않은 문제 의 발생시에는 이를 효과적으로 해결하기 위해 제공되는 지 식들을 융통성 있게 통합하여 추론하도록 요구하게 된다.

따라서, 본 연구에서는 위에서 언급한 기존 적용영역과의 공통점을 바탕으로 $\mathrm{EID}$ 의 적용영역을 새로운 영역인 함정 레이더 디스플레이로 확대하고자 한다. 이를 위하여 함정 레 이더 인터페이스에 대한 Work Domain Analysis(WDA)를 실시하여 Work Domain Model(WDM)을 개발하고 디자인 을 위한 Information Requirement(IR)를 추출하여 새로운 정보 내용들이 포함된 레이더 디스플레이를 개발하여 실제 로 함정 레이더 운용에 있어 수행시간, 정확도, 정신적 작업 부하 측면에서 어떠한 효과가 있는지 평가하였다.

\section{Theoretical Background}

\subsection{Ecological Interface Design(EID)}

EID (Ecological Interface Design)는 인간 작업자와 기 계보다는 작업자와 작업환경 사이의 상호작용을 강조하는 생태학적 접근 방법을 기초로 하여, 복잡한 사회공학적 (sociotechnical) 시스템 인터페이스를 디자인하기 위하여 개발되었다. $\mathrm{EID}$ 를 디스플레이 설계에 적용할 때 선행되어야 하는 것이 디스플레이에 포함되는 정보간의 관계를 확인하 기 위한 작업분석(Work Analysis)이다(Vicente, 2002). 작업분석방법에는 시스템의 목적을 달성하기 위해 사용자에 게 요구되는 행동 또는 수행과정을 확인하는 직무분석(Task Analysis) 과 시스템이 일반적이지 않은 상황 또는 작업환경 의 변화에 직면할 때 사용자가 적절한 대응을 할 수 있도록 디스플레이를 디자인 하기 위한 인지작업분석(Cognitive Work Analysis, CWA) 등이 있다(Kirwan and Ainsworth, 1992; Vicente, 1999). 이때 직무분석의 경우 일반적인 상 황이나 사건에 대해서는 적절한 분석을 가능하게 하지만, 일 반적이지 않은 상황이나 사건에 대해서는 분석이 제한된다 (Vicente and Rasmussen, 1992). 따라서 본 연구에서는 작업환경이 역동적이고 변화가 많은 해군 함정의 특성을 고 려하여 인지작업분석 (CWA)을 실시하였다. CWA는 시스템 의 제한사항과 수행 가능 범위에 따라 (1) Work Domain Analysis(WDA), (2) Cognitive Task Analysis (CTA), (3) Strategies Analysis(SA), (4) Social Organization and Cooperation Analysis (SOCA), (5) Worker Competencies Analysis (WCA)의 5단계로 이루어진다. 이 중 $\mathrm{WDA}$ 는 $\mathrm{CWA}$ 5단계 중 가장 기본적이면서 중요한 단계로, 디스플레 이를 포함한 각종 인터페이스 디자인 설계와 관련하여 밀접
한 관계가 있는 단계이다(Vicente, 1999).

\subsection{Work Domain Analysis(WDA)}

WDA (Work Domain Analysis)의 주된 기능은 시스템의 목적과 시스템이 만족시켜야 하는 가치와 우선순위를 확인 하고, 시스템이 본질적으로 가지고 있는 제한사항들을 식별 하는 것이다(Vicente, 1999). 시스템의 WDA를 위한 효과 적인 방법으로 Rasmussen(1985)이 제안한 Abstraction Hierarchy (AH) 가 있다. AH는 (1) Functional Purpose(왜 이 시스템이 설계되었는가?), (2) Abstract Function(시스템 작동의 일반적 원리), (3) Generalized Function(시스템의 일 반적 기능), (4) Physical Function(일반적 기능을 실행하기 위한 시스템의 설비 및 장비), (5) Physical Form(Physical Function의 위치 및 외적 특성)의 다섯 수준으로 나누어진 다. 이때 각 수준의 구성 요소는 means-end(수단-목적) 의 관계, 즉 why-what-how로 연결된다(Rasmussen and Vicente, 1989). 이러한 $\mathrm{AH}$ 를 통해 WDA의 결과인 Work Domain Model(WDM)이 도출된다.

\section{EID for Radar Display System}

\subsection{System description}

Ecological Interface Design(EID)는 작업자를 중심으로 하는 다른 디자인 방법론과 다르게 작업자의 작업환경을 면 밀히 분석함으로써 디스플레이 개발에 필요한 정보를 추출 하는 방법론이다(Vicente and Rasmussen, 1992). 그러므 로 EID를 위한 Work Domain Analysis(WDA)의 대상이 되는 시스템의 경계 즉, 작업영역의 경계에 대한 결정은 개 발하려고 하는 디스플레이의 종류와 사용자들이 디스플레이 를 이용하여 수행할 수 있는 행위에 영향을 주게 된다. 그러 므로 시스템 분석의 목적, 주어진 문제의 종류, 분석 결과의 활용 방법 등에 따라 분석될 시스템의 경계가 다르게 결정될 수 있다(Vicente, 2002). 따라서 시스템의 경계를 결정하는 것은 $\mathrm{WDA}$ 를 하는데 있어서 첫 번째 중요한 단계이다. 본 연구는 현재 해군에서 운용중인 레이더 디스플레이(SPA$99 \mathrm{~K}$ )를 기반으로 하였으며, 작전임무(대공 - 대함 - 대잠 · 전자전) 와 일반항해 (협수로 항해, 인명구조 등) 와 같은 다양 한 목적으로 운용되는 레이더 운용 분야 중, 함정의 전투력 운용과 관련되어 있는 군사 작전 관련 분야는 제외하였고 항 해와 관련 있는 대함 레이더 디스플레이 분야에 초점을 맞춰 진행하였다. 따라서, 교전 상황이나 대공, 대잠 작전 등의 작 전 상황 제외하였으며, 함정의 일반항해 상황 중 일반적이지 


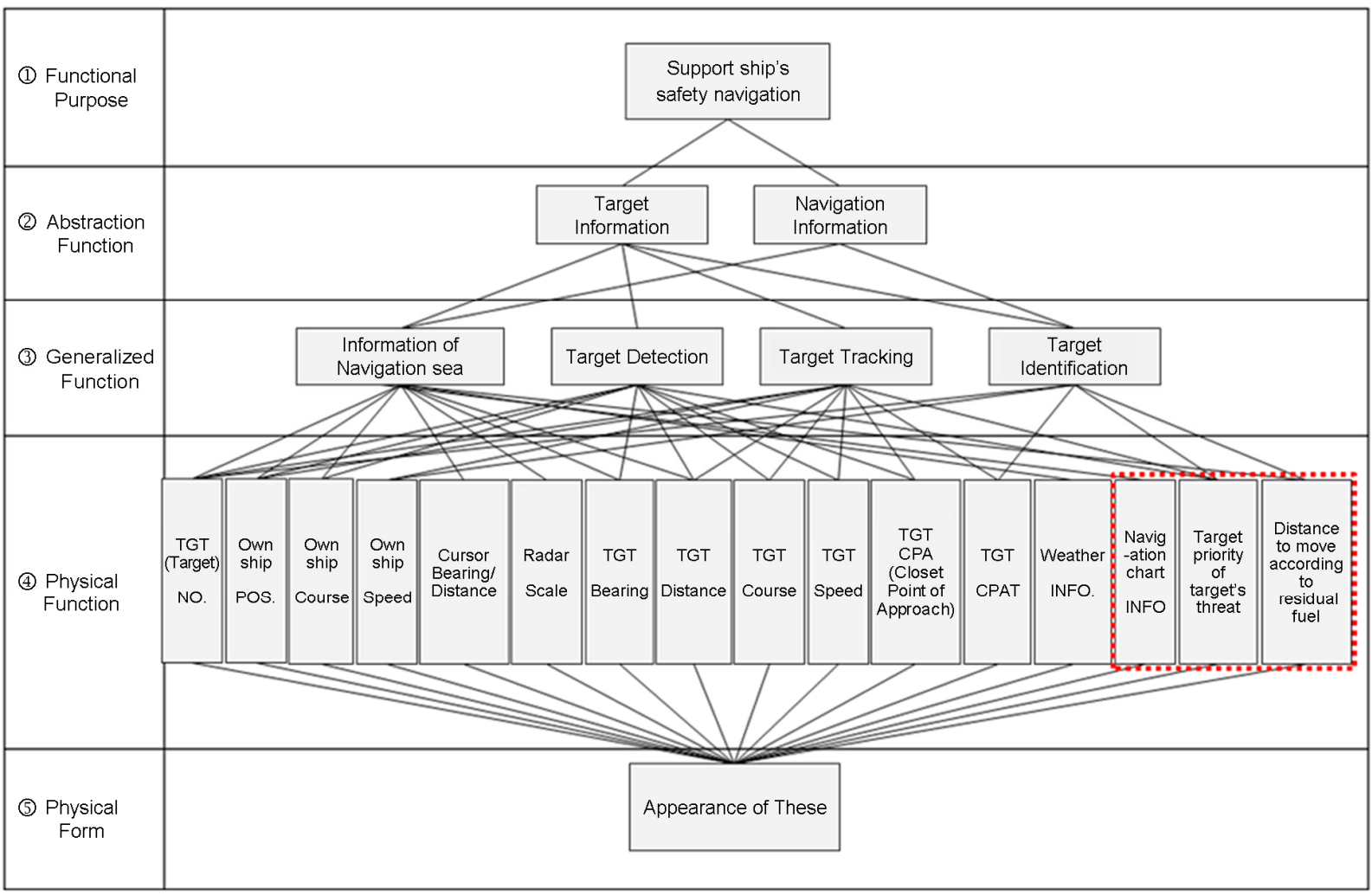

Figure 1. Work domain model

않은 상황이 발생할 상황이 높은 협수로 항해 상황을 중심으 로 $\mathrm{WDA}$ 를 위한 시스템 경계를 설정하였다.

\subsection{Information gathering}

본 연구에서는 효과적인 WDA(Work Domain Analysis) 를 위해 현재 해군에서 사용하고 있는 레이더 작업자 교육 교재, 레이더 시스템의 운용절차에 대한 각종 교범, 함정 출 · 입항 메뉴얼, 레이더 디스플레이 디자인 및 성능에 관련 된 교범 등을 조사하였다. 또한, 레이더 작업자에 대한 교육 · 훈련 임무를 수행하고 있는 전문가를 통해 요구기능과 관 련된 의견을 조사하였다.

\subsection{Abstraction Hierarchy(AH)}

Rasmussen(1985)이 제안한 $\mathrm{AH}$ 를 기초로 하여 WDM 을 개발하기 위해서는 $\mathrm{AH} 5$ 계층의 기능(Function)들을 도 출하는 것이 선행되어야 한다(Burns and Hajdukiewicz, 2004). Figure 1은 본 연구를 통해 도출된 해군 레이더 시 스템의 WDM을 보여준다.

먼저, Figure 1의 Functional Purpose는 $\mathrm{AH}$ 의 첫 번째
단계로, 작업 시스템이 존재하는 이유가 무엇인가에 관한 것 이며 이는 시스템의 목적과 일치한다. 해군 레이더 인터페이 스는 함정의 안전항해가 가능토록 지원하는 임무를 수행한 다. 따라서 Figure 1의 (1)과 같이 함정이 안전하게 항해할 수 있도록 지원하는 것을 Functional purpose로 정하였다.

둘째, Abstract Function은 작업 시스템이 목적을 달성하 고 있는지 판단 기준, 즉, Functional Purpose의 목적과 관 계된 기능들의 결과가 바람직하게 나타났는지 판단할 수 있 는 기준이다. 함정 레이더 디스플레이의 운용에 있어서 함정 레이더 인터페이스의 목적인 함정의 안전항해 지원을 위해 서 표적 정보를 확인하고 함정이 위치하고 있는 해역의 항 해 정보를 파악해야 한다. 이 사항을 기준으로 Figure 1의 (2)와 같이 Abstraction Function을 표적에 관한 정보, 항해 에 관한 정보로 정하였다.

Generalized Function은 작업영역의 목적 수행을 위한 원 리나 법칙들이 어떠한 실질적인 절차들로 실행되고 있는지 나타내는 것이다. 함정 레이더 인터페이스에서 Generalized Function에 해당하는 정보는 Figure 1의 (3)과 같이 해역 정 보, 표적 탐지, 표적 추적, 표적식별 정보이다.

Physical Function은 절차들의 수행이 어떠한 장비나, 구 성 요소들로 사용으로 이루어지고 있으며, 그것들의 능력 
은 어느 정도인지 나타내는 것이다. 이를 기준으로 Physical Function은 자함 위치, 이동방향, 속력, 해도 정보 등의 16 가지로 정하였다. 마지막 Physical Form은 작업 시스템을 구성하는 물리적 대상의 위치, 기능, 정보 등을 나타내기 위 해 사용되는 그래픽 요소들을 나타내고 있다.

위와 같이 도출한 각각의 계층들을 means-ends 관계, why-what-how 관계를 이용하여 연결하였다. 어떤 계층 에 해당하는 기능일 지라도 바로 상위에 인접한 계층의 기 능은 왜 이것이 필요한가에 대한 대답이며, 하위 계층에 해 당하는 기능에 대해서는 어떻게 이것이 달성될 수 있는가에 대한 대답이 된다.

\subsection{Evaluation of Work Domain Model(WDM)}

지금까지 $\mathrm{WDA}$ 를 통해 완성된 $\mathrm{WDM}$ 에 대한 평가를 실 시하여 $\mathrm{WDM}$ 이 얼마나 작업영역을 반영하는 지를 확인하 였다. 본 연구에서는 Burns et al.(2001)에 의해 고안된 Scenario Mapping 법을 사용하였다. Scenario Mapping법 은 특정 시나리오를 주고, 그 시나리오를 해결하기 위한 성 공적인 의사결정시 요구되는 사항들이 $\mathrm{WDM}$ 에 제시되어 있 는지 각각의 $\mathrm{AH}$ 의 수준들을 따라가면서 확인하는 방법이다. 본 연구에서는 5년 이상의 함정 레이더 오퍼레이터 임무 수 행 경력을 가진 4 명의 영역전문가를 대상으로 평가에 대한 목적 설명 및 동의서 작성 후 평가를 실시하였다. 사용된 시 나리오는 Table 1 과 같이 함정의 항해 상황에 초점을 맞춘 총 다섯 가지의 사건으로 구성하였다.

Table 1. Scenarios for scenario mapping test

\begin{tabular}{c|l}
\hline No. & \multicolumn{1}{|c}{ Scenario } \\
\hline 1 & $\begin{array}{l}\text { Approach of a number of high-speed targets in a narrow } \\
\text { channel }\end{array}$ \\
\hline 2 & Sudden fuel leakage in a narrow channel \\
\hline 3 & Navigation in low water level areas of a seas \\
\hline 4 & $\begin{array}{l}\text { Own ship drifted to low water level areas of the seas by } \\
\text { malfunctioning of rudder }\end{array}$ \\
\hline 5 & Unidentified target is detected in low visibility navigation \\
\hline
\end{tabular}

Scenario Mapping법 결과 각각의 시나리오 해결을 위한 의사결정시 요구되는 정보들이 WDM의 범위 안에서 전개 되고 설명됨을 확인하였다. 따라서 완성된 $\mathrm{WDM}$ 은 본 연 구의 목적에 적절함을 확인하였다. Figure 2는 scenario 4 번에 대한 Scenario Mapping 테스트의 결과의 예이다.

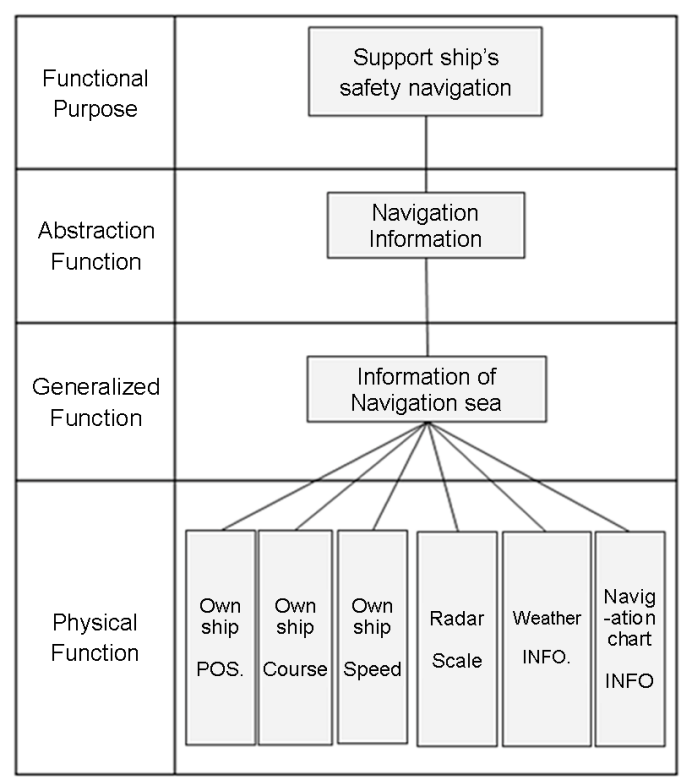

Figure 2. Example of the results scenario mapping test

\subsection{Extracting Information Requirements(IR)}

Scenario Mapping 법을 통해 확인된 WDM을 바탕으로 해군 함정 레이더 디스플레이 설계를 위해 필요한 요구 정보 (IR)를 추출하였다. 요구 정보 추출을 위해 6 10년 경력의 해군 함정 레이더 오퍼레이터 임무를 수행한 전탐사 5명을 대상으로 전문가 인터뷰를 실시하였다. 상위 계층의 기능들 은 시스템의 주목적에 직접적으로 연관된 기능이다. 그러나 그 기능에 관련된 정보들은 시스템으로부터 직접적으로 얻 기 힘든 경우가 많다. 또한 하위 계층의 기능과 관련된 정보 들은 시스템으로부터 습득하기는 용이하지만, 시스템의 목적 과 관련성이 낮다. 현재 해군 레이더 디스플레이에서 제공하 는 정보들은 시스템의 주목적인 함정의 안전 운항과 직접적 인 관련이 적고, 종합적인 정보를 제시하는데 제한적이다. 그에 따라 디스플레이 작업자들은 제시된 정보를 가지고 추 론 및 통합해야 하는 과정을 거쳐야 함으로 정신적인 인지부 하가 크게 된다. Table 2는 추출된 요구 정보(IR)를 표시하 고 있다. 이중, 1 13번까지의 정보는 현재 레이더 디스플레 이에서 제공하는 정보로 WDM의 Physical Function에서 확인할 수 있는 정보이다. 14 16 기존 레이더 디스플레이에 서는 제공하지 않는 정보이며 $\mathrm{WDM}$ 에서의 위치 역시 기존 의 정보와 마찬가지로 Physical Function이다. 하지만, 기존 정보들은 레이더 인터페이스 자체에서 얻어지는 정보인 반 면, 새로운 정보들은 레이더 인터페이스에서 얻을 수 없는 정보들이다. 이러한 정보들은 기존 레이더 인터페이스에서 제공되는 정보와 통합된 정보의 형태로 나타나게 되어, 작업 
자가 주어진 정보를 가지고 추론 및 통합하는 과정을 줄여준 다고 할 수 있다.

Table 2. Information requirements

\begin{tabular}{c|c}
\hline & IR \\
\hline 1 & Target Number \\
\hline 2 & Own ship position \\
\hline 3 & Own ship Course \\
\hline 4 & Own ship Speed \\
\hline 6 & Cursor Bearing/Distance \\
\hline 7 & Radar scale change \\
\hline 8 & Target Bearing \\
\hline 9 & Target Distance \\
\hline 10 & Target Course \\
\hline 12 & Target Speed \\
\hline 13 & Target CPAT \\
\hline 14 & Weather Information \\
\hline 15 & Navigation chart Information \\
\hline 16 & The priority of target's threat \\
\hline
\end{tabular}

\subsection{EID display}

Figure 3은 기존 방식의 디스플레이로써 여기에는 표적들 의 침로, 속력, $\mathrm{CPA}, \mathrm{CPAT}$ 등 주로 각 표적들의 현재 이동 상태와 자함을 기준으로 한 정보 요소들이 포함되어 있다. 반면, Figure 4의 EID 디스플레이는 기존 디스플레이에서 사용하고 있는 정보에 $\mathrm{WDA}$ 를 통해 식별된 상위 수준의 정 보 내용들을 추가하였다. 즉, Table 2의 요구 정보(IR) 중 기존 레이더 인터페이스에서 제공하지 않는 해도 정보, 잔여 연료에 따른 이동 가능 거리, 표적 위협 우선순위에 관한 정 보를 추가하였다. 이때 본 연구에서는 EID 디스플레이의 구 현을 위한 세부적인 Graphical User Interface(GUI)에 관 한 연구는 제외하고 기존 디스플레이에 $\mathrm{WDA}$ 를 통해 식별 된 요구 정보의 내용들을 추가하여 $\mathrm{EID}$ 디스플레이를 구현 하는 방식으로 연구를 진행하였다. 그 이유는 본 논문의 목 적이 새로운 $\mathrm{EID}$ 디스플레이의 개발이라는 application 관 점보다는, 해군 레이더 레이더 인터페이스에 처음으로 $\mathrm{EID}$ 방법론을 적용해 보고자 하는 이론적인 측면을 강조하였기 때문이다. 이러한 방식의 기존 논문으로는 Ko and Myung (2006) 등이 있다. 구체적으로 EID 디스플레이에는 Figure 4 의 (1)과 같이 항해하는 해역의 해도 정보를 전시하도록 하 여 레이더 작업자가 항해 중 일반적이지 않은 상황에 직면시
에 필요한 정보(저수심, 암초 등)를 시각적으로 쉽고 빠르게 얻을 수 있도록 하였다. 또한 Figure 4의 (2)와 같이 각 표적 들의 충돌 수준을 3 순위까지 계산하여 전시하도록 하고 레 이더 작업자가 설정한 위협 수준 이상으로 표적이 접근시 시각적으로 구분되도록 하였다. 마지막으로 Figure 4의 (3) 과 같이 최종 목적지까지의 거리, 함정에 남아 있는 연료량 을 기준으로 주행 가능 거리를 표시하고, 표적과의 충돌 같 은 비상상황 발생으로 최종 목적지까지 도착하기 전에 연료 가 소모되는 상황을 사전에 처리하여 가장 적절한 속력을 나 타내도록 하였다.

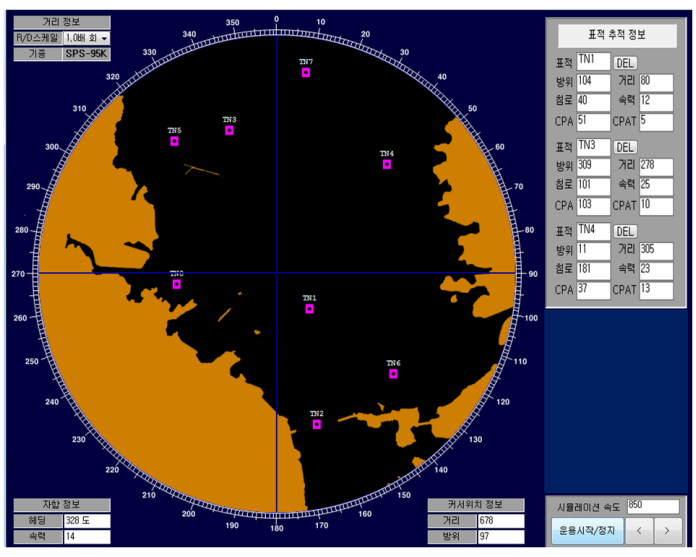

Figure 3. A traditional radar display

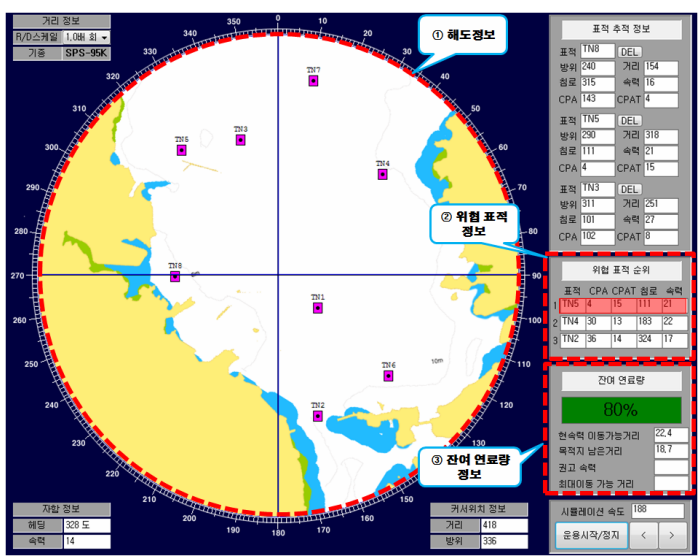

Figure 4. An ecological radar display

\section{Method}

본 연구에서는 기존 디스플레이와 EID 디스플레이가 수행 
도(Performance Time, Score) 및 정신적 작업부하 측면에 서 어떠한 차이가 있는지 확인하기 위한 실험을 실시하였다.

$\mathrm{EID}$ 개념에 따르면, 작업환경의 분석을 통해 얻어진 수준 별 정보 내용을 인터페이스 개발에 사용하는 것은 작업자의 의사결정을 지원할 수 있는 인터페이스 디자인에 필수적인 요소라고 강조하고 있다. 하지만, 작업자에게 더 많은 정보 를 제공한다는 것이 반드시 더 좋은 수행도를 이끌어 내는 것은 아니며, 추가적인 정보가 작업자에게 도움을 제공할 때만이 더 좋은 수행도를 나타낼 수 있는 것이다(Wickens and Holland, 2000).

따라서, 기존 디스플레이와 EID 디스플레이의 수행도 및 정신적 작업부하를 측정하여 결과를 비교, 분석하였다.

\subsection{Participants}

피실험자는 군 경력이 평균 8.5년( \pm 3.7$)$ 이며, 함정 레이 더 운용경험이 평균 6.8 년 $( \pm 2.6)$ 인 28 40세 사이의 현역 남성 부사관 10 명으로 구성하였다.

\subsection{Apparatus}

실험에 사용된 Simulation 프로그램은 Visual Basic을 사용하여 구현하였으며, 레이더 디스플레이는 화면은 24 인 치 모니터에 추가 정보사항들은 15.4 인치 노트북을 통하여 제공하였다. 실험에 사용한 해도는 일반 항해시 사용되는 Navionics 전자 해도 프로그램을 사용하였다.

\subsection{Experimental design}

실험은 기존방식의 디스플레이와 새로 개발된 EID 디스플 레이가 피실험자의 임무수행에 있어 어느 정도의 차이를 가 지고 있는지 평가하였으며, 2수준의 디스플레이 Type과 2 수준의 복잡도를 독립변수로 하여 복잡도가 높고 낮음에 따 라 각 디스플레이의 수행도가 어떻게 변하는지 조사하였다. 10 명의 피실험자를 대상으로 Two Factor Within Subject 로 디자인하였다. 복잡도 수준은 현재 해군 교육사에서 레이 더 작업자를 교육중인 전문가의 의견을 바탕으로 디스플레 이 상에 레이더 작업자가 실제로 통제하고 있는 표적의 대 수를 기준으로 삼아 1 수준은 복잡도가 낮은 수준인 3 대로 하였고, 2 수준은 복잡도가 높은 수준인 8 대를 기준으로 하 였다.

실험을 위해 항해시 안전항해를 위해 필수적으로 요구되 는 정보사항을 평가하기 위해 전문가 3 명의 의견을 종합하 여 Table 3 과 같이 10 개의 문항을 작성하였다. Table 3 의 1 5는 항해시의 일반적인 상황에 관한 문제이며, 6 10은
일반적이지 않은 상황에 관한 문제이다. 임무 시나리오를 고 려하여 1 번과 8 번 문항이 1 회씩 추가되도록 하였고, 그에 따라 각 실험당 피실험자가 해결해야 할 문제의 수는 총 12 문제였다.

Table 3. Questionnaires for experiments

\begin{tabular}{c|l}
\hline NO. & \multicolumn{1}{c}{ Question } \\
\hline 1 & $\begin{array}{l}\text { How many targets do make contact with own ships on } \\
\text { radar? }\end{array}$ \\
\hline 2 & How much is the current depth of water level? \\
\hline 3 & What is the target which has the smallest CPA? \\
\hline 4 & What is the fastest target \\
\hline 5 & $\begin{array}{l}\text { Do you detect a change of residual fuel on current } \\
\text { display? }\end{array}$ \\
\hline 7 & $\begin{array}{l}\text { What is the fastest approaching target without bearing } \\
\text { changes? }\end{array}$ \\
\hline 8 & $\begin{array}{l}\text { The fuel is leaking by a collision with unidentified } \\
\text { object. How much is the recommended speed } \\
\text { considering the residual fuel? }\end{array}$ \\
\hline 9 & $\begin{array}{l}\text { Which target is the first to collide with own ship } \\
\text { considering the current state? }\end{array}$ \\
\hline 10 & $\begin{array}{l}\text { The rudder is out of action. } \\
\text { What is smallest degree of bearing to shore? }\end{array}$ \\
\hline
\end{tabular}

\subsection{Procedures}

피실험자들에게 실험의 목적, 내용, 실험 방법을 설명하고, 동의서를 작성토록 하였다. 개인신상에 대한 설문지를 작성 하여 신체적 결함 등 피실험자로써 특이사항이 있는지 확인 하였다. 또한, 실험장비 운용의 숙달을 위해 20분간의 연습 시간을 제공하였으며, 총 4 번의 실험 중 각 실험 사이에 10 분간의 휴식시간을 제공하여 피로도에 따른 에러를 방지하 였다. 추가적으로 실험순서를 counterbalancing하여 학습효 과에 따른 에러를 방지하였다.

또한, 피실험자로 하여금 실제 항해와 동일한 상황을 가정 하여 실험을 하도록 유도하였고, 실제 상황을 묘사하기 위해 Figure 5 와 같이 함정이 (1) $\rightarrow$ (2) $\cdots \rightarrow$ (5)를 이동하는 환경을 프로그램을 통해 구현하였다. 실험 중 일정한 시간에 화면이 정지되도록 하여 화면에 질문이 나타나도록 하였다. 이때 피 실험자는 화면에 나타나는 질문을 확인하고 문제해결 후 4 지선다형 답안을 선택하게 된다. 이때 문제를 해결하기까지 의 시간(Performance Time)과 정확도(Score)를 측정하였 다. Figure 6는 실험 중 실험자가 수행해야 할 문제가 나타 난 화면이다. 또한, 실험이 종료된 후 NASA-TLX 설문지 
를 사용하여 각 디스플레이에 대한 피실험자의 정신적 작업 부하를 측정하였다.

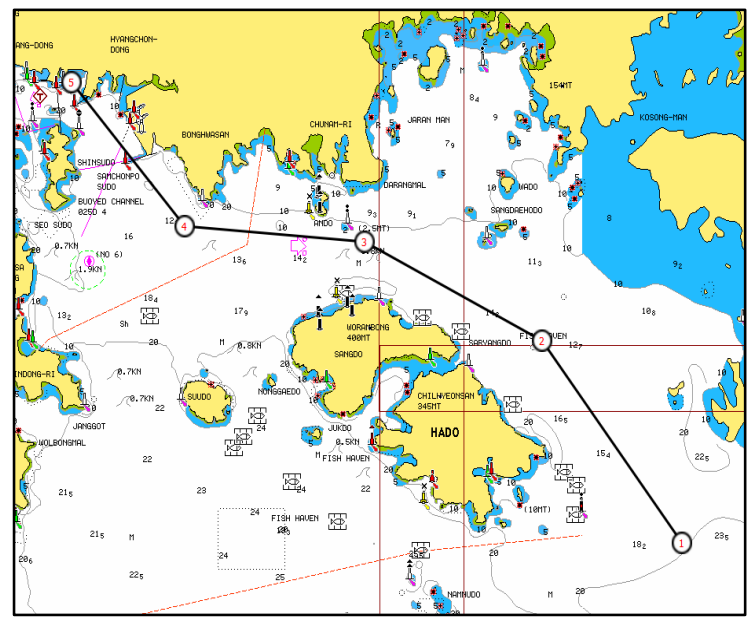

Figure 5. Overview of electronic navigation chart

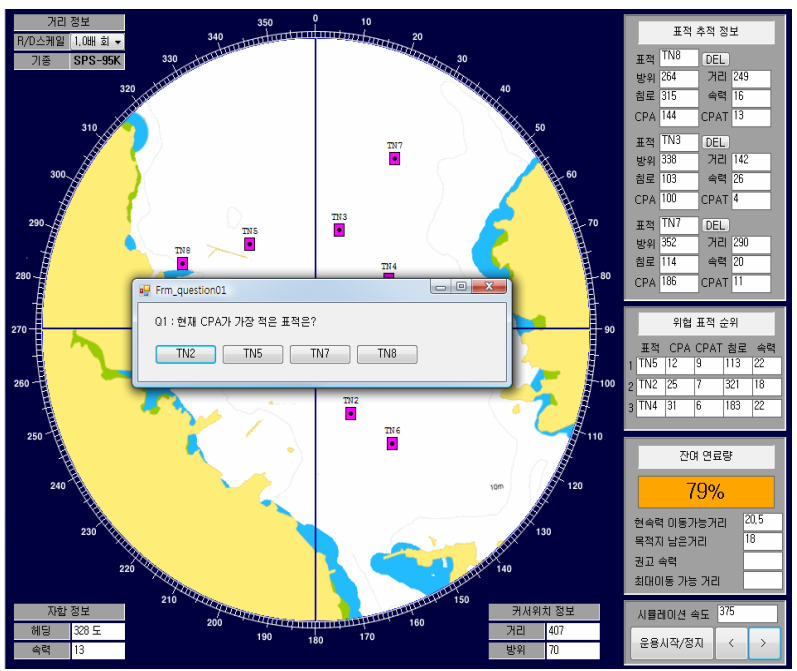

Figure 6. Detailed view of electronic navigation chart

\section{Results}

\subsection{Performance Time(PT)}

EID 디스플레이와 기존 디스플레이를 구분하여 일반적인 상황과 일반적이지 않은 상황에서 $\mathrm{PT}$ 결과를 측정하였다. 분석한 문제의 수는 앞의 experimental design에서 설명한 대로 일반적인 상황과 일반적이지 않은 상황 각각 6 문제였
다(Table 3). Figure 7에서 알 수 있듯이 PT는 EID 디스플 레이가 일반적인 상황(EID: 16.6(11.6, 기존: 36.6(17.0)과 일반적이지 않은 상황(EID: 12.3(4.3, 기존: 43.0(11.1) 모 두에서 기존 디스플레이 비해 빠른 수행 결과를 보였다. 세 부 분석 내용은 다음과 같다. 먼저, Table 4 를 보면 일반적 인 상황과 일반적이지 않은 상황 모두에서 종속변수인 PT 에 대해 디스플레이 타입과 복잡도간에 교호작용이 유의하 지 않게 $(p$-value $=0.297,0.494)$ 나왔다.
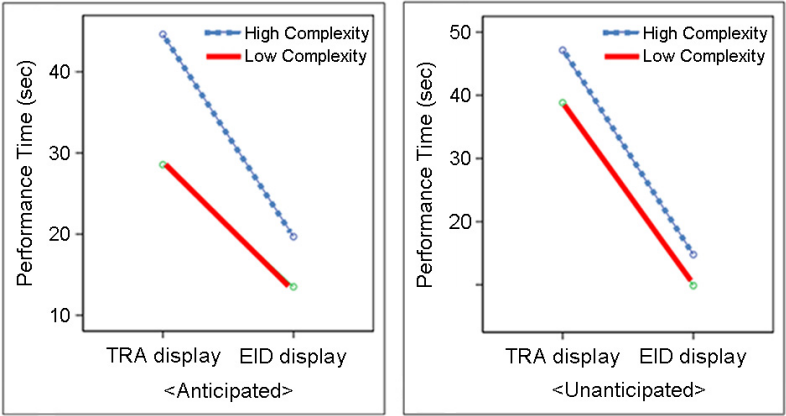

Figure 7. Anticipated vs. unanticipated

이것은 주 효과 분석 (main effect test)을 실시하는 것은 의미가 있다는 것을 뜻하며, 그에 따른 주 효과 분석 결과 를 보면, Table 4 에서 보는 바와 같이 각각의 독립변수들 (display type, complexity)이 종속변수인 PT에 미치는 영향이 유의한 것으로 나타났다 $(p$-value < 0.05$)$. 이것은, $\mathrm{EID}$ 디스플레이와 기존 디스플레이간에는 유의한 차이가 있 다는 것을 의미한다.

Table 4. PT ANOVA table with $p$-values

\begin{tabular}{c|c|c}
\hline & $\begin{array}{c}p \text {-value of } \\
\text { anticipated }\end{array}$ & $\begin{array}{c}p \text {-value of } \\
\text { unanticipated }\end{array}$ \\
\hline Display Type & .001 & .000 \\
\hline Complexity & .010 & .008 \\
\hline Display Type * Complexity & .297 & .494 \\
\hline
\end{tabular}

위의 실험 결과를 통해 $\mathrm{EID}$ 디스플레이가 기존 디스플레 이에 비해 실험자로 하여금 복잡도 및 상황 발생 정도의 여 부에 상관없이 모든 상황에서 통계적으로 유의하게 빠른 수 행을 보임을 알 수 있었다. 이것은 EID 디스플레이가 기존 디스플레이보다 더 효과적인 디스플레이이라고 할 수 있는 근거가 될 수 있을 것이다. 


\subsection{NASA-TLX}

NASA-TLX 결과는 EID 디스플레이(20.9(12.7)가 기 존 디스플레이(38.7(15.8)에 비해 복잡도에 상관없이 실험 자의 정신적 잡업부하를 유의하게 낮은 상태로 유지되도록 하였다. Table 5는 NASA-TLX에 대한 ANOVA 분석 결 과이다.

Table 5. NASA-TLX ANOVA table with p-values

\begin{tabular}{c|c}
\hline & $p$-value of NASA-TLX \\
\hline Display Type & .001 \\
\hline Complexity & .000 \\
\hline Display Type * Complexity & .193 \\
\hline
\end{tabular}

Table 5 를 보면 디스플레이 타입과 복잡도간의 교호작용 이 유의하지 않으므로 $(p-$ value $=0.193)$. 주 효과 분석은 의미가 있다. 그에 따른 주 효과 분석의 결과를 보면, Table 5 에서 보는 바와 같이 각각의 독립변수들(display type, complexity)이 종속변수인 NASA-TLX에 미치는 영향이 유의한 것으로 나타났다 $(p$-value<0.05). 이는 Figure 8 에서 볼 수 있듯이 EID 디스플레이가 기존 디스플레이에 비 하여 복잡도의 변화에 관계없이 실험자의 정신적 작업부하 를 유의하게 낮은 수준으로 유지시켜줌을 알 수 있다.

또한, Figure 8의 (1)과 (2)는 복잡도 증가에 따른 $\mathrm{EID}$ 디스 플레이와 기존 디스플레이의 NASA-TLX 값의 변화도를 나타내는데, EID 디스플레이가 복잡도 증가에 따라 Figure 8 의 (1)과 같이 $9.3(16.23 \rightarrow 25.53)$ 의 변화를 보이는 반면, 기존 디스플레이는 $16.74(30.33 \rightarrow 47.07)$ 의 변화를 보이고 있다. 이는 $\mathrm{EID}$ 디스플레이가 복잡도가 증가하더라도 기존 디스플레이에 비해 작업자의 정신적 작업부하를 일정하게

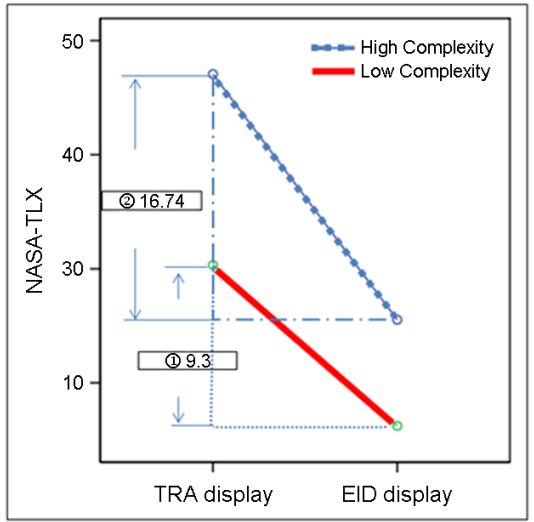

Figure 8. NASA-TLX
낮게 유지시켜 주고 있음을 의미한다고 할 수 있다.

다음으로 PT와 NASA-TLX의 상관관계를 확인하기 위 하여 둘간의 상관분석을 실시하였다. PT와 NASA-TLX간 의 상관계수는 0.58 이었다. 이는 피어슨 상관계수에서 설명 하고 있는 뚜렷한 양적 선형관계(0.3 0.7)의 범위에 포함된 다(Walpole et al., 2007). 이것은 PT값의 증가함에 따라 실험자가 받는 정신적 작업부하 역시 증가한다는 것을 의미 한다. 즉, 실험자가 어려운 문제를 해결하기 위해 시간을 소 모하는 만큼 정신적 작업부하도 많이 받는다는 것이다.

\section{Discussion}

첫째, 본 연구에서는 $\mathrm{EID}$ 를 해군 레이더 디스플레이의 설 계에 적용함으로써, 기존 핵발전소 process control system, 항공기 관제 시스템, 자동차 계기판 디스플레이 등에 적용되 었던 EID의 적용 분야를 확장하였다(Burns, et al., 2008a; Ko and Myung, 2006; Nam et al., 2007).

앞의 실험 결과를 보면, $\mathrm{EID}$ 디스플레이가 기존 디스플레 이에 비해 피실험자의 PT를 빠르게 하며, 낮은 정신적 작업 부하를 유발시킨다는 것을 알 수 있다. 이러한 결과는 본 연 구를 통해 개발한 $\mathrm{EID}$ 디스플레이가 작업자가 필요로 하는 정보만을 제공한다는 EID의 장점 (Vicente and Rasmussen, 1992)을 잘 반영한 결과라고 할 수 있다. 또한, 본 연구는 $\mathrm{EID}$ 를 적용하여 작업자의 수행도 향상과 낮은 정신적 작업 부하를 확인한 다른 영역의 연구 결과와도 일치하는데 (Ko and Myung, 2006; Nam, et al., 2007; Vicente, 2002), 이 러한 사항을 토대로 볼 때 본 연구의 결과는 해군 레이더 디 스플레이 영역에도 $\mathrm{EID}$ 를 적용할 수 있다는 것을 뒷받침 해 준다고 할 수 있다.

둘째, 상황인식 (Situation Awareness, SA)에 관한 사항 이다. 일반적으로 좋은 상황인식은 높은 수행도를 보이지만, 그것이 필연적인 것은 아니다(Venturino, 1990; Endsley, $1995 b)$. 하지만 EID를 통해 개발된 디스플레이는 수행도 향상과 더불어 $\mathrm{SA}$ 를 향상시키는 결과를 보이며 $(\mathrm{Li}$, et al., 2007; Roth et al., 2001), 특히 일반적이지 않은 상황에서의 $\mathrm{SA}$ 향상에 효과가 있다(Burns, et al., 2008b). 따라서 본 연구에서는 상황인식을 실제적으로 측정하지는 않았지만, 수 행도와 정신적 작업부하의 향상이라는 연구 결과는 $\mathrm{EID}$ 를 통해 운용자의 상황인식이 개선되었기 때문이라고 해석할 수 있는 것이다.

셋째, 본 연구는 기존 국내 EID 연구 분야(Ko and Myung, 2006; Nam et al., 2007) 와는 달리 일반적인 상황과 일반 적이지 않은 상황을 구분하여 수행도를 측정하였다. 한편, 
본 연구와 같이 일반적인 상황과 일반적이지 않은 상황을 구 분하여 수행도를 측정한 기존 Burns et al.(2008a)의 연구 결과에서는 일반적이지 않은 상황에서 수행도가 EID 디스 플레이보다 기존 디스플레이가 더 좋게 나왔다. 그 이유는 Burns et al.이 연구한 핵 발전소 시스템은 확인해야 할 정보 가 많았기 때문에 피실험자가 EID 디스플레이에 충분히 익 숙해지지 못했기 때문이라고 생각된다. 반면, 본 연구의 EID 디스플레이는 피실험자가 확인해야 할 정보가 상대적으로 적었기 때문에 피실험자가 쉽게 EID 디스플레이에 익숙해 질 수 있었고, 그에 따라 일반적인 상황과 일반적이지 않은 상황 모두에서 $\mathrm{EID}$ 디스플레이가 기존 디스플레이보다 수 행이 향상되었다고 생각된다. 따라서 본 연구는 작업자가 $\mathrm{EID}$ 디스플레이에 충분히 익숙해진다면 일반적인 상황과 일 반적이지 않은 상황 모두에서 수행이 향상될 수 있음을 설명 한다고 할 수 있을 것이다.

넷째, 본 연구에서는 문제해결의 정확도(Score) 측정하였 지만, 예상과는 달리 통계적으로 유의한 차이를 보이지 않았 다. 하지만, 이것이 $\mathrm{EID}$ 가 과제 수행의 정확도 증가에 효과 가 없었기 때문이라기 보다는 피실험자가 시간이 더 소요되 더라도 문제를 더 정확히 해결하고자 노력한 결과, speedaccuracy trade-off에 의한 것으로 해석된다(Wickens and Holland, 2000). 이러한 원인은 실험 디자인 측면에 있어서 문제당 시간 제한(time limitation)이 없었기 때문에 발생 하였다고 생각되는데, score에 대한 정확한 측정을 위해서 는 문제당 고정된 시간(fixed given time)이 주어져야 하 지만, 본 연구에서는 실험자가 문제해결을 할 때까지의 시 간(completion time)을 측정하도록 하였기 때문이다. 따라 서 향후 $\mathrm{EID}$ 와 과제 수행의 정확도와의 관계를 연구하고자 할 때는 과제 수행시간을 통제한 실험이 수행되어야 할 것 이다.

\section{Conclusion}

본 연구의 결과는 다음과 같다.

먼저, $\mathrm{EID}$ 적용 분야를 해군 레이더 디스플레이 분야까지 확장하였다.

또한, EID 디스플레이가 기존 디스플레이보다 일반적인 상황은 물론 일반적이지 않은 상황에서도 수행을 개선시킬 수 있었으며, 정신적 작업부하를 적게 유발한다는 것을 알 수 있었다.

\section{References}

Bennett, K. B., et al. Visual display, In: G. Salvendy(Ed), Handbook of human factors and ergonomics, $2^{\text {nd }}$ ed., New York: John Wiley and Sons, 1997.

Burns, C. M. and Vicente, K. J., Physical and functional displays in process supervision and control(CEL 95-11), Technical Report Cognitive Engineering Group, University of Toronto, Department of Industrial Engineering, 1995.

Burns, C. M., Putting it all together: Improving display integration in ecological displays, The Journal of the Human Factors and Ergonomics Society, 42(2), 226-241, 2000.

Burns, C. M., Bryant, D. J. and Chalmers, B. A., "Scenario mapping with work domain analysis", Proceedings of the $45^{\text {th }}$ Annual Meeting of the Human Factors and Ergonomics Society, (pp. 424-428), Minneapolis, Minnesota, 2001.

Burns, C. M. and Hajdukiewicz, J. R., Ecological Interface Design, New York: CRC Press, 2004.

Burns, C. M., Bryant, D. J. and Chalmers, B. A., Boundary, Purpose, and Values in Work-Domain Models: Models of Naval Command and Control, IEEE Transactions on Systems, Man and Cybernetics - Part A: Systems and Humans, 35(5), 603-616, 2005.

Burns, C. M., Lau, N., Jamieson, G. A. and Skraaning, G. Jr., Ecological Interface Design in the Nuclear Domain: An Empirical Evaluation of Ecological Displays for the Secondary Subsystems of a Boiling Water Reactor Plant Simulator, IEEE Transactions on Nuclear Science, 55(6), 3597-3610, 2008a

Burns, C. M., Skraaning, G. Jr., Jamieson, G. A., Lau, N., Kwok, J., Welch, R. and Andresen, G., Evaluation of Ecological Interface Design for Nuclear Process Control: Situation Awareness Effects, The Journal of the Human Factors and Ergonomics Society, 50(4), 663-679, 2008b.

Chen, H. W. and Burns, C. M., "Work Domain Analysis for the Interface Design of a Sonobuoy System", Proceedings of the $51^{\text {st }}$ Annual Meeting of the Human Factors and Ergonomics Society, (pp. 283 -287), Guelph Ontario, Canada, 2007.

Endsley, M. R., "Predictive utility of an objective measure of situation awareness", Proceedings of the $34^{\text {th }}$ Annual Meeting of the Human Factors and Ergonomics Society, (pp. 41-45), Santa Monica, USA, 1990.

Endsley, M. R., Towards a theory of situation awareness in dynamic systems, The Journal of the Human Factors and Ergonomics Society, 37(1), 32-64, 1995a.

Endsley, M. R., "A taxonomy of situation awareness errors", Humanfactors in aviation operations; Proceedings of the $21^{\text {st }}$ Conference of the European Association for Aviation Psychology, (pp. 287-292), Dublin, Ireland, 1995b.

Gibson, J. J., The ecological approach to visual perception. New Jersey: Lawrence Erlbaum Associates, 1979.

Goodstein, L. P., Discriminative display support for process operators. In: Rasmussen J, Rouse WB(Ed). Human detection and diagnosis of system failure, New York: Plenum Press, 1981. 
Ham, D. H. and Yoon, W. C., The Effect of Presenting Functionally Abstracted Information in Fault Diagnosis Tasks, Reliability Engineering and System Safety, 73(2), 103-119, 2001.

Kirwan, B. and Ainsworth, L. K., A guide to task analysis, London: Taylor and Francis, 1992.

Ko, S. M. and Myung, R. H., Ecological Interface Design for Air Traffic Control Display, Journal of the Ergonomics Society of Korea, 25(4), 103-113, 2006.

Lee, S. W., Lee, B. G., Back, J. S., Jo, S. S. and Myung, R. H., Applying Work Domain Analysis for Ecological Interface Design of Safety Monitoring System in the Urban Railway Station, Journal of the Korean Society for Railway, 13(3), 265-270, 2010.

Li, X., Sanderson, P., Memisevic, R. and Wong, W., "Adapting situational awareness measures for hydropower display evaluations", Proceedings of the Human Factors and Ergonomics Society $51^{\text {st }}$ Annual Meeting (pp. 210-214), Santa Monica, CA, 2007.

Nam, T. S., Myung, R. H. and Hong, S. K., The Application of Work Domain Analysis for the Development of Vehicle Control Display, Journal of the Ergonomics Society of Korea, 26(4), 127-133, 2007.

Naikar, N., Hopcroft, R. and Moylan, A., Work Domain Analysis: Theoretical Concepts and Methodology, DSTO-TR-1665, 2005.

Roth, E. M., et al. Designing a first-of-a-kind group view display for team decision making: A case study. In E. Salas \& G. Klein (Eds.), Linking expertise and naturalistic decision making, Mahwah, NJ: Erlbaum, 2001.

Rasmussen, J., The role of hierarchical knowledge representation in decisionmaking and system management, IEEE Transactions on Systems, Man and Cybernetics, 15(2), 234-243, 1985.

Rasmussen, J. and Vicente, K. J., Coping with human errors through system design: Implications for ecological interface design, International Journal of Man-Machine Studies, 31(5), 517-534, 1989.

Upton, C. and Doherty, G., Extending Ecological Interface Design Principles: A Manufacturing Case Study, International Journal of HumanComputer Studies, 66(4), 271-286, 2008.

Venturino, M., Williaml, H. and Stephenr, D., "Performance-based measures of merit for tactical situation awareness", Proceeding of the Situation Awareness in Aerospace Operations, (pp. 23-53), Guelph Ontario, Canada, 1990.

Vicente, K. J. and Rasmussen J., The ecology of human-machine systems II: mediating direct perception in complex work domains, Ecological Psychology, 2(3), 207-49, 1990.

Vicente, K. J. and Rasmussen, J., Ecological interface design: theoretical foundations, IEEE Transactions on Systems, Man and Cybernetics, 22(4), 589-606, 1992.

Vicente, K. J., Cognitive Work Analysis: Toward Safe, Productive and Healthy Computer-Based Work, Mahwah, NJ: Erlbaum and Associates, 1999.

Vicente, K. J., Ecological Interface Design: Progress and Challenges, Human Factors, 44(1), 62-78, 2002.

Walpole, R. E., et al. Probability \& Statistics for Engineers \& Scientists, $8^{\text {th }}$ ed, Pearson Education International, 2007.

Wickens, C. D. and Hollands, J. G., Engineering Psychology and Human Performance, Prentice Hall, 2000.

Woods, D. D., The cognitive engineering of problem representations, In: Weir G. R. S. and Alty J. L.(Ed), Human-computer interaction and complex systems, New York: Academic Press, 1991.

\section{Author listings}

Young Hwan Park: kaiser57@korea.ac.kr

Highest degree: B. S., International Relations, Republic of Korea Naval Academy

Position title: M. S., School of Industrial Management Engineering, Korea University

Areas of interest: Ecological Interface Design, Cognitive Ergonomics

Rohae Myung: rmyung@korea.ac.kr

Highest degree: $\mathrm{Ph}$. D., Industrial Engineering, Texas Tech University Position title: Professor, School of Industrial Management Engineering, Korea University

Areas of interest: Cognitive Engineering, $\mathrm{HCI}$

Date Received : 2011-11-02

Date Revised : 2011-12-01

Date Accepted : 2011-12-01 